\title{
Sex differences in stress-induced gastric ulceration: Effects of castration and ovariectomy
}

\author{
NAOTO KIMURA, HIROYUKI YOSHIMURA, and NOBUYA OGAWA \\ Ehime University School of Medicine, Ehime, Japan
}

\begin{abstract}
The present study investigated sex differences in susceptibility to stress-induced ulcers. Gastric mucosal lesions were produced in mice and rats through the use of a paradigm in which some animals were shocked and others were exposed to stimuli arising from the shocked animals. Under these conditions, shocked and nonshocked animals showed an approximately equal incidence of gastric lesions. There were significant differences between the sexes in the incidence of gastric lesions following stress, with males of both species showing a higher incidence of ulceration. Castration reduced the severity of ulceration in males, but ovariectomy had no effect on ulceration in females. The data suggest that male sex hormones play an important role in the development of gastric lesions in both mice and rats under the experimental conditions employed.
\end{abstract}

Various experimental manipulations have been devised for producing gastric ulcers in laboratory animals. Although social and psychological factors are presumed to play an essential role in pathogenesis, such psychological components as fear or anxiety have not been isolated (for a review, see Mikhail, 1980). The experimental methods that have been used in studies of ulceration (conditioned fear, conflict, avoidance, etc.) make it difficult to exclude a direct contribution of physical stressors, such as electric shock, to ulcer development.

We recently developed a communication box paradigm that allows us to distinguish the contributions of physical stimuli and conditioned fear to the development of stressinduced ulcers (Ogawa, Yoshimura, Pack, \& Tsunekawa, 1984; Yoshimura, Kan, \& Ogawa, 1986). The box consists of several small compartments divided by transparent Plexiglas. The grid floors in half of the compartments are covered with Plexiglas to prevent electric footshocks; the remaining floors are uncovered (Ogawa \& Kuwahara, 1966). This allows nonshocked animals to be exposed to affective stimuli such as visual, auditory, and olfactory cues from the shocked conspecifics. In this situation, a high incidence of gastric mucosal lesions is observed not only in the shocked animals, but also in the nonshocked animals, a result that rules out direct effects of the shock as a cause of ulcer production. Furthermore, the gastric lesions produced in the communication box paradigm are limited to the glandular portion of the stomach, and appear to be similar to the gastric lesions induced by acute

This research was supported in part by a grant from the Pharmacopsychiatry Research Foundation, Japan. We thank Misuzu Kurokawa and Ichizo Matsuzaki for skillful technical assistance and animal care. Requests for reprints should be addressed to Hiroyuki Yoshimura, Department of Pharmacology, Ehime University School of Medicine, Onsen-gun, Ehime 791-02, Japan. stress in humans. We therefore believe that we have a satisfactory model for studying the factors that affect ulcer production in humans.

Physicians have noticed that the incidence of gastric ulceration in humans is different in males and females, with males showing a higher incidence of ulceration (e.g., Kronberger \& Hafner, 1966). There has been, however, little information concerning sex differences in the development of experimental ulcers. The present study was conducted to investigate possible sex differences in susceptibility to gastric ulceration induced by physical and/or psychological stresses in our paradigm, using mice (Experiment 1A) and rats (Experiment 1B).

\section{EXPERIMENT 1A}

\section{Method}

Subjects. All animals employed were male and female ICR mice. The mice were housed communally in conventional polycarbonate cages ( 5 animals per cage), with unrestricted access to food and water. The temperature in the vivarium was maintained at $23^{\circ} \pm 1^{\circ} \mathrm{C}$, and a 12 -h light-dark cycle was automatically controlled (light on at 7:00 a.m., off at 7:00 p.m.).

Apparatus. The communication box $(60 \times 60 \times 46 \mathrm{~cm})$ was made of white Plexiglas with a floor constructed of stainless steel grids. The box was divided into 36 compartments $(10 \mathrm{~cm}$ square and $46 \mathrm{~cm}$ high) by transparent Plexiglas partitions. The floors in half of the compartments were covered with gray Plexiglas plates to prevent electric footshock; the floors of the remaining $18 \mathrm{com}$ partments were uncovered.

Behavioral procedure. Prior to the introduction of mice into the box, all animals were deprived of food for $12 \mathrm{~h}$. All animals, placed individually in compartments, were given a pure tone $(2000 \mathrm{~Hz}$, $10 \mathrm{sec}$ ) as the conditioned stimulus. Then the mice in the physically stressed group (PHYS-STRESS group), which had been placed on the uncovered floors, were given electric footshocks of $10 \mathrm{sec}$ duration (1.5 mA every $120 \mathrm{sec}$ for the first $6 \mathrm{~h}$ and $2.0 \mathrm{~mA}$ for the next $6 \mathrm{~h}$ ), with a light signaling shock onset. An incandescent bulb (25 W) mounted $30 \mathrm{~cm}$ above the box was used as the light 
signal; the intensity of illumination was approximately $200 \mathrm{~lx}$ at the center of the box. The mice in the psychologically stressed group (PSYCH-STRESS) were placed on the covered floors and received the pure tone and light signal, along with affective stimuli (e.g., startle response and vocalization) arising from the shocked mice. The conditioned emotional stimulus was applied repeatedly at 120 -sec intervals for $12 \mathrm{~h}(7: 00$ p.m. to 7:00 a.m.). In this experiment, 36 mice were used in each stress-loading. Thus, intact males $(n=18)$ were paired with intact females $(n=18)$, sham-castrated males $(n=18)$ were paired with castrated males $(n=18)$, and sham-ovariectomized females $(n=18)$ were paired with ovariectomized females $(n=18)$. In each treatment group, half the mice were randomly assigned to PHYS-STRESS and the remainder were assigned to PSYCH-STRESS.

Surgical procedure. Castrations and ovariectomies were performed immediately after weaning (when the mice were 21-22 days of age). For the castration, the male mouse was anesthetized with ether and placed on its dorsal surface without restraint. A small $0.8-1.0 \mathrm{~cm}$ transverse incision was made across the abdomen. The fat with the caput epididymis was grasped and the testis was pulled out through the muscle incision. A ligature was placed round the blood vessels and the vas deferens, and both the testes and epididymes were resected bilaterally. For removal of the ovaries, the female mouse was anesthetized with pentobarbital $(65 \mathrm{mg} / \mathrm{kg}$, i.p.) and placed on its ventral surface without restraint. A small $1.0-1.5-\mathrm{cm}$ midline incision was made in the skin, and a muscle incision was made using small scissors and forceps. The periovarian fat was grasped and the ovary was pulled out through the muscle incision. The ovaries were resected bilaterally using an electrocauterizer. The shamoperated animals underwent the same procedure as the castrated or ovariectomized mice, but without resection of the target organ.

Observation of gastric lesions. One hour after termination of stress loading, the mice were killed with chloroform. After the stomach was quickly resected and filled with $1.5 \mathrm{ml}$ of saline, the ballooned stomach was immersed in a $10 \%$ formaldehyde solution for $5 \mathrm{~min}$. The lightly fixed specimen was cut along the greater curvature, and gastric lesions were inspected macroscopically. The gastric lesions were classified, on the basis of their shapes, as linear, petechial, or none.

Statistical analysis. Statistical evaluation was performed by means of the nonparametric Mann-Whitney $U$ test (two-tailed criterion).

\section{Results}

As shown in Figure 1, males and females in both the PHYS-STRESS and PSYCH-STRESS groups differed in the incidence and severity of gastric lesions, with lesions being more frequent in the male mice $(p<.01)$. Females did not manifest linear lesions, and only 3 of the 9 females in the PHYS-STRESS group and 2 of the 9 females in the PSYCH-STRESS group showed petechial lesions. There was no significant difference in the development of gastric lesions between the PHYS-STRESS and PSYCH-STRESS groups.

Castration significantly affected the incidence and severity of gastric lesions in male mice. In the PHYSSTRESS group, only 1 of the 9 castrated males manifested linear lesions, whereas only 2 of them did not show any mucosal lesions. In both the PHYS-STRESS and the PSYCH-STRESS groups, low incidence of gastric lesions in the castrated males was statistically reliable as compared with the corresponding sham-operated males $(p<.05)$.

Neither the incidence nor the severity of gastric lesions in the female mice was affected by ovariectomy. In a comparison of the ovariectomized females with the cor-
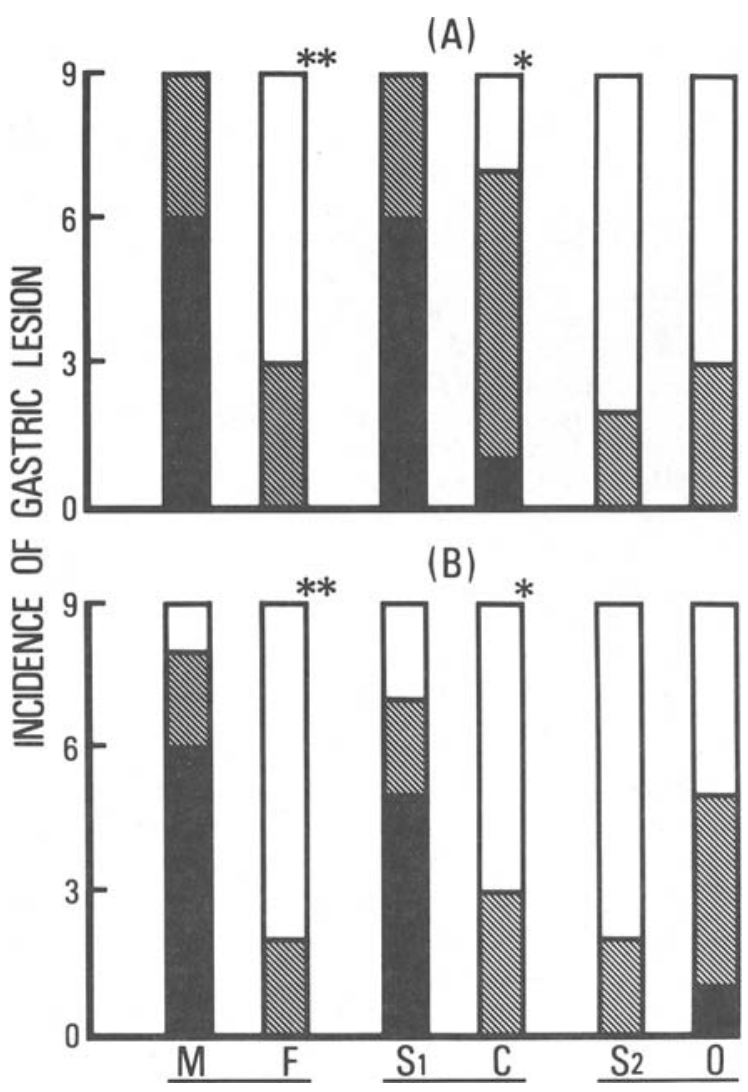

Figure 1. Comparison of the incidence of gastric lesions between male and female mice $(M=$ intact males, $F=$ intact females, $S 1$ $=$ sham-operated males, $\mathbf{C}=$ castrated males, $\mathbf{S 2}=$ sham-operated females, $\mathbf{O}=$ ovariectomized females). (A) Physically stressed group. (B) Psychologically stressed group. The open portions of the columns show the number of mice without gastric lesions; the hatched portions show the number of mice with petechial lesions; and the solid portions show the number of mice with linear lesions $\left({ }^{*} p<.05\right.$ and ${ }_{* *} p<.01$, as compared with the corresponding control, MannWhitney $U$ test).

responding sham-operated females, the ovariectomized females in the PSYCH-STRESS group showed a tendency toward an increased incidence of gastric lesions.

\section{EXPERIMENT 1B}

\section{Method}

Subjects. The subjects were 96 Long-Evans male and female rats. They were housed communally in conventional polycarbonate cages (4 animals per cage), with unrestricted access to food and water. All other conditions were the same as those in Experiment $1 \mathrm{~A}$.

Apparatus. The size of the communication box was the same as in Experiment 1A, but the box was divided into 16 compartments $(15 \mathrm{~cm}$ square and $46 \mathrm{~cm}$ high) by Plexiglas partitions. The floors of half of the compartments were covered; those of the remaining 8 were uncovered.

Behavioral procedure. Before being introduced into the box, all animals were deprived of food for $24 \mathrm{~h}$ and treated with an intraperitoneal injection of reserpine $(1 \mathrm{mg} / \mathrm{kg}$ twice per day, at 0800 and $1800 \mathrm{~h}$ ), which does not produce gastric lesions by itself (Pack, 
1984). The intensity of the 10 -sec footshocks was $2.0 \mathrm{~mA}$ every $120 \mathrm{sec}$ for the first $6 \mathrm{~h}$ and $2.5 \mathrm{~mA}$ for the next $6 \mathrm{~h}$. The conditioned stimuli were the same as those used in Experiment $1 \mathrm{~A}$. In Experiment 1B, each stress loading was performed using 16 rats; half of each treatment group were randomly assigned to PHYSSTRESS $(n=8)$, and half were assigned to PSYCH-STRESS $(n=8)$. The other procedures were the same as those used in Experiment $1 \mathrm{~A}$.

Surgical procedure. Castration and ovariectomy were performed using the procedures of Experiment $1 \mathrm{~A}$, except that the fernale rats were anesthetized with pentobarbital $(40 \mathrm{mg} / \mathrm{kg}$, i.p.).

Observation of gastric lesions. Observation of the gastric lesions followed the procedures of Experiment $1 \mathrm{~A}$, except that the stomach was filled with $6 \mathrm{ml}$ of saline.

Statistical analysis. Statistical analysis was done using the twotailed Mann-Whitney $U$ test.

\section{Results}

The sex differences found in the development of gastric lesions in mice were also observed in rats (Figure 2). The difference between intact male and female rats, however, was not statistically significant. In the PHYSSTRESS group, the incidence of linear lesions in females was about half that in males, whereas in the PSYCHSTRESS group, the incidence was almost the same.

In both PHYS-STRESS and PSYCH-STRESS, the incidence and severity of gastric lesions were significantly suppressed by castration $(p<.05)$. In particular, the number of rats with linear lesions was markedly decreased.

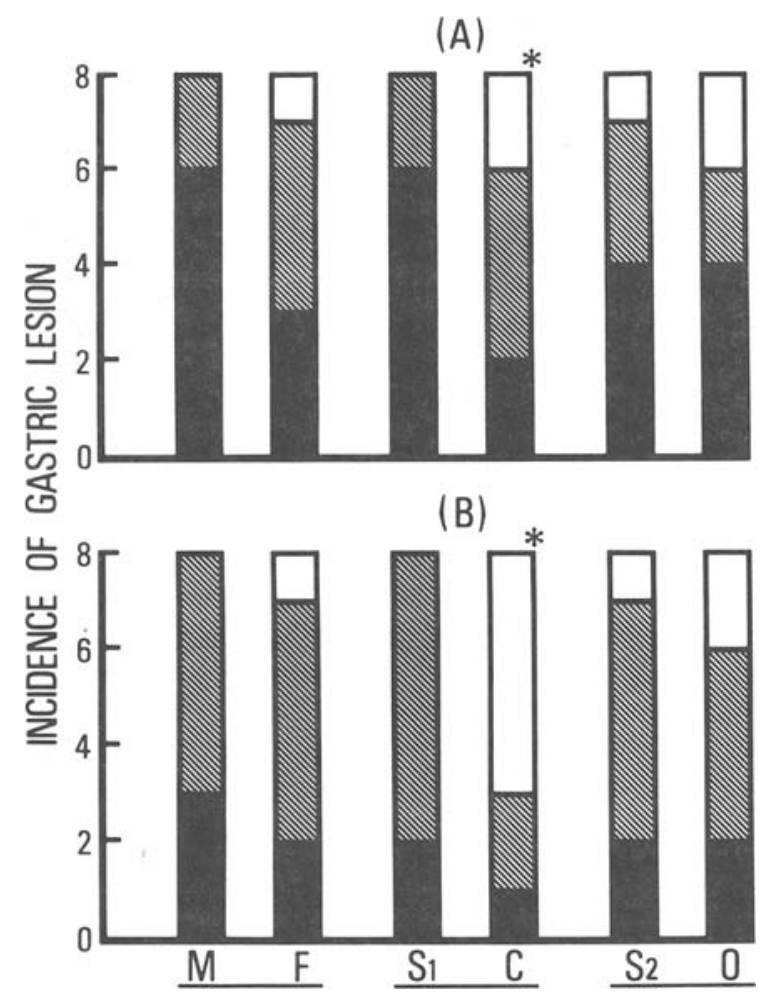

Figure 2. Comparison of the incidence of gastric lesions between male and female rats. For abbreviations, see Figure 1 caption.
Ovariectomy did not affect the incidence or severity of gastric lesions in either group, and there was no significant difference between sham-operated and ovariectomized females.

\section{DISCUSSION}

Sex differences in the development of stress-induced ulcers were previously reported by Paré, Vincent, Isom, and Reeves (1978), who used an activity-wheel paradigm and found that the incidence of gastric lesions was higher in female rats than in males. They explained this difference by noting that females exhibited higher spontaneous activity in the running-wheel, and thus reached the lesion-inducing peak activity level more rapidly than the males. The present experiments clearly demonstrated that there are sex differences in both the incidence and the severity of gastric lesions, with the susceptibility to stressinduced ulcers being greater in male mice and rats. Since the development of gastric lesions in our procedure closely correlated with sensitivity to emotional stimuli, the discrepancy between Paré et al.'s findings and ours may be a result of the different stressors used to produce the gastric lesions. In this regard, sex differences in emotional response to external stimuli have been reported by several investigators (Archer, 1975; Beatty \& Beatty, 1970; Gray, 1971).

The present finding that castration decreased both the incidence and the severity of gastric lesions in males suggests that male sex hormones participate in the mediation of gastric ulceration. Interestingly, there appear to be sex differences in adrenal cortical secretion that depend on gonadal hormone effects on pituitary-adrenal function (e.g., Kitay, 1961, 1963). Since the pituitary-adrenal axis is closely related to stress-induced behavioral and somatic changes, it is conceivable that androgens may modify the development of stress-induced ulcers through their effects on adrenal function. At present, there is little evidence as to whether androgens can directly modify the pathological changes in the gastric mucosa.

Female sex hormones, on the other hand, do not appear to participate in the mediation of gastric lesions induced in our paradigm. Ovariectomy did not affect either the incidence or the severity of the gastric lesions in females. There are inconsistent data concerning the effects of estrogens on the development of gastric lesions. For example, Manekar and Namaji (1977) found that estrogen and progesterone decreased gastric ulceration induced by histamine and pyloric ligation. In contrast to this finding, Antonsen (1955) reported that estrogen treatment increased the severity of gastric lesions induced by ligating the pylorus.

In most conditions of the present study, animals were run with same-sex conspecifics to evaluate the effect of each treatment on the development of stress ulcers. Since the magnitude of stress in nonshocked animals is affected by the emotional response of shocked animals, we cannot rule out the possibility that sex differences in response 
to shock may have contributed to the results we obtained. Further studies will be needed to analyze the potential contribution of this factor to sex differences in gastric ulceration.

\section{REFERENCES}

ANTONSEN, S. (1955). The influence of sex hormones on experimentally produced gastric ulcer in rats. Acta Endocrinologica, 19, 203-208.

ARCHER, J. (1975). Rodent sex differences in emotional and related behavior. Behavioral Biology, 14, 451-479.

Beatty, W. W., \& Beatty, P. A. (1970). Hormonal determinants of sex differences in avoidance behavior and reactivity to electric shock in the rat. Journal of Comparative \& Physiological Psychology, 73, 446-455.

GRAY, J. A. (1971). Sex differences in emotional behavior in mammals including man: Endocrine base. Acta Psychologica, 35, 29-46.

KITAY, J. I. (1961). Sex differences in adrenal cortical secretion in the rat. Endocrinology, 68, 818-824.

KITAY, J. I. (1963). Pituitary-adrenal function in the rat after gonadectomy and gonadal hormone replacement. Endocrinology, 73, 253-260.

KRONBERGER, L., \& HAFNER, H. (1966). Influence of female sex hormones on ulcers of upper gastrointestinal tract. Endokrinologie, 49, 185-198.

Manekar, M. S., \& Namaji, K. I. (1977). Effect of female sex hor- mones in experimentally induced acute gastric ulceration. Indian Journal of Medical Research, 65, 894-899.

Mikhail, A. (1980). Psychological stress and stomach ulcer: In search of an hypothesis. Brain Research Bulletin, 5, 67-71.

Ogawa, N., \& Kuwahara, H. (1966). Psychophysiology of emotioncommunication of emotion. Journal of the Japanese Psychosomatic Society, 6, 352-357.

Ogawa, N., Yoshimura, H., Pack, S. J., \& Tsunekawa, K. (1984). A new experimental model of stress ulcers: A communication box paradigm using the conditioned emotional stimuli. Annual Report of the Pharmacopsychiatry Research Foundation, 15, 22-29.

PAck, S. J. (1984). Gastric mucosal lesions in rats induced by the communication box paradigm: Experimental conditions, endoscopic observation and effect of vagotomy. Folia Pharmacologica Japonica, 83, 467-478.

Paré, W. P., Vincent, G. P., Isom, K. E., \& Reeves, J. M. (1978). Sex differences and incidence of activity-stress ulcers in the rat. Psychological Reports, 43, 591-594.

Yoshimura, H., Kan, N., \& OGaWa, N. (1986). Effect of anxiolytic drugs on the development and healing process of stress ulcer: Application of endoscopic observation. Folia Pharmacologica Japonica, 87, 583-597.

(Manuscript received July 3, 1986; revision accepted for publication April 28, 1987.) 